\title{
Advanced mathematics \\ 3
}




\section{Advanced mathematics \\ 3}

C W Celia

formerly Principal Lecturer in Mathematics, City of London Polytechnic

A T F Nice Mathematics Department, Lady Eleanor Holles School, Hampton; formerly Principal Lecturer in Mathematics, Middlesex Polytechnic

K F Elliott

formerly Head of the Division of Mathematics Education, Derby Lonsdale College of Higher

Education

Consultant Editor: Dr C. Plumpton, Moderator in Mathematics, University of London School Examinations Board: formerly Reader in Engineering Mathematics; Queen Mary College, London

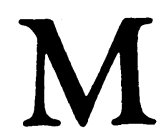


All rights reserved. No reproduction, copy or transmission of this publication may be made without written permission.

No paragraph of this publication may be reproduced, copied or transmitted save with written permission or in accordance with the provisions of the Copyright, Designs and Patents Act 1988, or under the terms of any licence permitting limited copying issued by the Copyright Licensing Agency, 33-4 Alfred Place, London WC1E 7DP.

Any person who does any unauthorised act in relation to this publication may be liable to criminal prosecution and civil claims for damages.

First edition 1985

Reprinted 1986, 1991

Published by

MACMILLAN EDUCATION LTD

Houndmills, Basingstoke, Hampshire RG21 2XS

and London

Companies and representatives

throughout the world

British Library Cataloguing in Publication Data

Celia, C.W.

Advanced mathematics.

3

1. Mathematics-1961-

I. Title II. Nice, A. T. F.

III. Elliott, K. F.

$510 \quad$ QA39.2

ISBN 978-0-333-34827-7

DOI 10.1007/978-1-349-06711-4

ISBN 978-1-349-06711-4 (eBook) 


\section{Contents}

Preface

vii

1 The idea of proof

Propositions Implication Necessary and sufficient conditions Relationship analysis Data sufficiency Solution of equations Methods of proof

2 Complex numbers

De Moivre's theorem Square roots and cube roots The $n$th roots of unity Conjugate complex numbers The exponential function Straight lines and circles in the Argand diagram The transformations $w=a z+b, w=1 / z, w=(a z+b) /(c z+d)$

3 Hyperbolic functions

Properties of functions $\operatorname{Cosh} x \operatorname{Sinh} x$ Tanh $x$ Summary of properties Inverse hyperbolic functions Applications to integration

4 Differential equations

Separable equations First-order linear differential equations Linear differential equations with constant coefficients Integral curves Applications Vector differential equations

5 Polar coordinates

The straight line The circle The angle $\phi$ between tangent and radius vector Curve sketching Area of a sector

6 Sequences and series: convergence

Convergence of sequences and of series Tests for convergence of series of positive terms Comparison test Ratio test Convergence of integrals Maclaurin's series Taylor series Repeated differentiation Leibnitz's theorem

\section{Further integration and applications}

Definite integrals Reduction formulae Length of arc Area of surface of revolution Mean values First moments Theorems of Pappus 
8 Equations and inequalities

Roots of equations Further inequalities Inequalities in two variables The calculus applied to inequalities

9 Numerical solution of differential equations

Isoclines The Euler method The modified Euler method The Taylor series method Second-order equations Order of convergence

10 Coordinate geometry

The rectangular hyperbola $x y=c^{2}$ Tangent and normal The hyperbola $x^{2} / a^{2}-y^{2} / b^{2}=1$ Tangent and normal The ellipse $x^{2} / a^{2}+y^{2} / b^{2}=1$ Tangent and normal Change of axes The equations $a x^{2}+2 h x y+b \dot{y}^{2}=0$ and $a x^{2}+2 h x y+b y^{2}=1$ Tangents at the origin

11 Algebraic structure

Groups Symmetry groups Subgroups and cyclic groups Permutation groups Isomorphism Rings and fields

12 Vector spaces

Linear dependence Vector spaces

13 Determinants and matrices

Determinants of order 2 and order 3 Properties of matrices The inverse of a matrix Linear transformations in three dimensions Orthogonal matrices Eigenvectors of a matrix Diagonalisation of a matrix Quadratic forms

14 The vector product

The vector product Distributive law The vector product in component form Perpendicular distance from a point to a straight line The scalar triple product The vector triple product

Notation

Formulae

Answers

Index 


\section{Preface}

This is the third of a series of books written for students preparing for A level Mathematics. Book 1 covers the essential core of sixth-form mathematics now accepted by the GCE Boards, while Book 2 covers the applied mathematics, i.e. the numerical methods, mechanics and probability, contained in most singlesubject mathematics syllabuses.

Book 3 covers the additional pure mathematics needed by students taking the double subject Mathematics and Further Mathematics, and by those taking Pure Mathematics as a single subject.

It must be emphasised that the reader is expected to be familiar with the use of a calculator, so that numerical work presents no difficulties.

The material is arranged under well-known headings and is organised so that the teacher is free to follow his or her own preferred order of treatment. The chapter contents are listed and an index is also provided to make it easy for both the teacher and the student to refer back rapidly to any particular topic. For ease of reference, a list of the notation used is given at the back of the book together with a list of formulae.

The approach in Book 3 is the same as in Books 1 and 2, each topic being developed mainly through worked examples. There is a brief introduction to each new piece of work followed by worked examples and numerous simple exercises to build up the student's technical skills and to reinforce his or her understanding. It is hoped that this approach will enable the individual student working on his or her own to make effective use of the books and the teacher to use them with mixed ability groups. At the end of each chapter there are many miscellaneous examples, taken largely from past A level examination papers. In addition to their value as examination preparation, these miscellaneous examples are intended to give the student the opportunity to apply the techniques acquired from the exercises throughout the chapter to a considerable range of problems of the appropriate standard.

We are most grateful to the University of London University School Examinations Board (L), the Associated Examining Board (AEB), the University of Cambridge Local Examination Syndicate $(C)$ and the Joint Matriculation Board (JMB) for giving us permission to use questions from their past examination papers. 
We are also grateful to the staff of Macmillan Education for the patience they have shown and the help they have given us in the preparation of these books.

C. W. Celia

A. T. F. Nice

K. F. Elliott 